\title{
Acoustical studies of binary liquid mixtures of p-chlorotoluene in benzene at different temperatures
}

\author{
G. Pavan Kumar ${ }^{1, \star}$, Ch. Praveen Babu ${ }^{1}$, K. Samatha ${ }^{1}$, A. N. Jyosthna, \\ K. Showrilu ${ }^{2}$ \\ ${ }^{1}$ Ultrasonic Laboratory, Department of Physics, Andhra University, Visakhapatnam - 530003, India \\ ${ }^{2}$ Physics Department, St. Theresa College, Eluru, Andhra Pradesh, India \\ *E-mail address: pavan.phy@gmail.com
}

\begin{abstract}
Ultrasonic velocities $(\mathrm{U})$, densities $(\rho)$, and coefficient of viscosities $(\eta)$ are measured for binary mixtures containing (i) p-chlorotoluene and (ii) benzene at $303.15 \mathrm{~K}, 308.15 \mathrm{~K}, 313.15 \mathrm{~K}$ and $318.15 \mathrm{~K}$ to understand the molecular interaction. Various acoustical parameters such as adiabatic compressibility $\left(\beta_{\mathrm{ad}}\right)$, free length $\left(\mathrm{L}_{\mathrm{f}}\right)$, acoustic impedance $(\mathrm{Z})$, free volume $\left(\mathrm{V}_{\mathrm{f}}\right)$, molar volume $\left(\mathrm{V}_{\mathrm{m}}\right)$, Rao's constant $(\mathrm{R})$, Wada's constant $(\mathrm{W})$ and internal pressure $\left(\pi_{\mathrm{i}}\right)$, are calculated from the measured values of $U, \rho$, and $\eta$. The trend in acoustical parameters also substantiates to asses strong molecular interactions.
\end{abstract}

Keywords: Ultrasonic velocity; thermodynamic parameters; p-chlorotoluene; molecular interactions

\section{INTRODUCTION}

Ultrasonic studies provide a wealth of information about the state of the liquid. Ultrasonic velocity measurement has been adequately employed to understand the nature of the molecular interactions in binary mixtures [1,2] and ionic interactions in aqueous electrolytic solutions [3]. Measurement of ultrasonic velocity and other acoustical properties can be related to physico-chemical behaviours and molecular interactions in a number of binary systems. In this paper, ultrasonic studies were carried out in the following binary mixture p-chlorotoluene with benzene at $303.15 \mathrm{~K}, 308.15 \mathrm{~K} 313.15 \mathrm{~K}$ and $318.15 \mathrm{~K}$. The acoustical parameters have been calculated for this binary mixture at different concentration of p-chlorotoluene

In recent work, the research programme on thermodynamic, thermo-acoustic and transport behaviour of binary liquid mixtures of industrially important components. In recent years, ultrasonic technique has become a powerful tool in providing information regarding the molecular behaviour of liquids and liquid mixtures owing to its ability of characterizing physicochemical behaviour of the medium [4-8,17-23].

When two or more liquids are mixed, there occur some changes in physical and thermodynamic properties because of change in volume, energy and molecular interactions. Ultrasonic velocity measurements in liquids provides an information about inter and intra 
molecular interactions. Thermodynamic parameters derived from these measurements are extremely used to study the molecular interactions in liquid systems, aqueous solutions and liquid mixtures.

The determination of thermodynamic, acoustic and transport properties of liquid systems from density and velocity measurements [9-10]. The measurements of density, ultrasonic velocity, viscosity and the thermodynamic properties derived from these are excellent tools to detect solute-solute and solute-solvent interactions.

Even though the ultrasonic velocity data do not provide enough information about the native and the relative strength of various types of intermolecular interionic interactions between the components, their derived parameters such as acoustical impedance, adiabatic compressibility, intermolecular free length, molar volume, Rao's Constant, Wada's Constant, internal pressure and free volume are very useful in the study of molecular interactions. In view of the above we have carried out systematic experimental investigations of the ultrasonic velocity, density and viscosity measurements of aromatic hydrocarbons of different concentrations at different temperatures. Here we have reported the results of our study on pchlorotoluene with benzene system.

\section{EXPERIMENTAL DETAILS}

All the chemicals used were of Analytical Reagent (AR) grade with minimum array of $99.9 \%$. The ultrasonic velocity $(\mathrm{U})$ in liquid and liquid mixtures have been measured using an ultrasonic interferometer (Mittal Enterprises, Model F-81) working at $2 \mathrm{MHz}$ frequency with an accuracy of $\pm 0.1 \mathrm{~ms}^{-1}$.

An electronically digital operated constant temperature water bath has been used to circulate water through the double walled measuring cell made up of steel containing the experimental solution at the desire temperature.

The density of pure liquids and liquid mixtures was determined using density gravity bottle with an accuracy of $\pm 0.1 \mathrm{Kgm}^{-3}$. An Ostwald's viscometer was used for the viscosity measurement of pure liquids and liquid mixtures with an accuracy of $\pm 0.0001 \mathrm{NSm}^{-2}$.

The temperature around the viscometer and density gravity bottle was maintained within $\pm 0.1 \mathrm{~K}$ in an electronically operated constant temperature water bath. All the precautions were taken to minimize the possible experimental errors.

From the measured values of ultrasonic velocity $(U)$, density $(\rho)$ and viscosity $(\eta)$. The Adiabatic Compressibility $\left(\beta_{\mathrm{ad}}\right)$, Internal Molecular Free Length $\left(\mathrm{L}_{\mathrm{f}}\right)$, Acoustical Impedance $(\mathrm{Z})$, Molar Volume $\left(\mathrm{V}_{\mathrm{m}}\right)$, Rao's Constant $(\mathrm{R})$, Wada's constant $(\mathrm{W})$, Viscosity $(\eta)$, internal pressure $(\pi)$ and free volume $\left(\mathrm{V}_{\mathrm{f}}\right)$ were calculated by using the following standard relations.

\section{1. Adiabatic compressibility $\left(\beta_{\text {ad }}\right)$}

$$
\beta_{a d}=\frac{1}{\rho U^{2}}
$$




\section{2. Intermolecular free length $\left(L_{f}\right)$}

$$
L_{f}=K\left(\beta_{a d}\right)^{1 / 2}
$$

where $K$ is temperature dependent constant called as Jacobson constant. The value of $K$ at the working temperatures of the experiment were calculated (MKS units) and they are given below:

Temperature $(\mathrm{K})$

Value of $\mathrm{K}$

$\begin{array}{cc}303.15 & 308.15 \\ 2.075 \times 10^{6} & 2.095 \times 10^{6}\end{array}$

313.15

$2.115 \times 10^{6}$
318.15

$2.135 \times 10^{6}$

2. 3. Specific acoustic impedance $(Z)$

$$
Z=\rho U
$$

2. 4. Molar volume of the liquid mixture $\left(V_{m}\right)$

$$
V_{m}=\frac{M_{e f f}}{\rho_{m i x}}
$$

$$
M_{e f f}=\frac{M_{1} X_{1}+M_{2} X_{2}}{X_{1}+X_{2}}
$$

where

$$
\mathrm{R}=\mathrm{V}_{\mathrm{m}} \mathrm{U}^{1 / 3}
$$

2. 6. Molar compressibility or Wada's constant (W) can be calculated by the relation

$$
W=\frac{M_{e f f}}{\rho \beta_{a d}^{1 / 7}}
$$

2. 7. Internal pressure $(\pi)$

$$
\pi_{i}=b R T\left(\frac{k \eta}{U}\right)^{1 / 2} \frac{\rho^{2 / 3}}{M_{e f f}^{7 / 6}}
$$


where $\mathrm{b}$ is packing factor $(\mathrm{b}=2), \mathrm{K}$ is a constant, which is independent of temperature and its value is $4.28 \times 10^{9}$ for all liquids, $\mathrm{R}$ is universal gas constant and $\mathrm{T}$ is absolute temperature.

\section{8. Free volume}

$$
V_{f}=\left(\frac{M_{e f f} U}{k \eta}\right)^{3 / 2}
$$

where $\mathrm{k}$ is a constant, which is independent of temperature and its value is $4.28 \mathrm{X} 10^{9}$ for all liquids.

\section{RESULTS AND DISCUSSION}

The experimentally measured values of Density $(\rho)$, Ultrasonic velocity (U), Viscosity $(\eta)$ and thermodynamic parameters Adiabatic compressibility $\left(\beta_{\mathrm{ad}}\right)$, Intermolecular free length $\left(L_{\mathrm{f}}\right)$, Acoustic impedance $(\mathrm{Z})$, Molar volume $\left(\mathrm{V}_{\mathrm{m}}\right)$, Rao's Constant $(\mathrm{R})$, Wada's constant $(\mathrm{W})$, Viscosity $(\eta)$, Internal Pressure $(\pi)$ and Free Volume $\left(\mathrm{V}_{\mathrm{f}}\right)$ of p-chlorotoluene with benzene binary liquid system at different temperatures at a frequency of $2 \mathrm{MHz}$ are presented in Table 1.

Density increases with increasing the concentration of $\mathrm{p}$-chlorotoluene with benzene at different temperatures and also it decreases with increasing the temperature [11]. It suggests that a solute-solvent interaction exists between p-chlorotoluene with benzene system. In other words the decrease in density may be interpreted to the structure maker of the solvent due to $\mathrm{H}$-bonding. The ultrasonic velocity decreases with increase in the concentration and also decreases with increase in temperature suggesting thereby strong association between solute and solvent molecules [8-10].

From the Table 1, the adiabatic compressibility and free length decreases with increasing mole fraction of the p-chlorotoluene. Which suggest that making and breaking of H-bonding [12]. The intermolecular free length depends upon the intermolecular attractive and repulsive forces [13]. Eyring and Kincaid [14] have proposed that $\mathrm{L}_{\mathrm{f}}$ is a predominating factor in determining the variation of ultrasonic velocity of solution. Hence it can be concluded that there is significant interaction between solute and solvent molecules due to which the structural arrangement is also affected. Thus it is clear from the above parameters that there is a strong association between $\mathrm{p}$-chlorotoluene and benzene system.

The acoustic impedance $(Z)$ increases with increase in concentration of $p$-chlorotoluene. It represents that there is strong interaction between the p-chlorotoluene and benzene system. In this system, viscosity increases with increasing molefraction of p-chlorotoluene and decreases with increasing temperature [15]. Viscosity with increase in concentration confirms that increase of cohesive forces because of strong interaction. The internal pressure decreases with increasing molefraction of p-chlorotoluene. This gives the information regarding the nature and strength of forces existing between the molecules. The increase in free volume indicates that the strength of interaction of molecules in this system. 
Table 1. Ultrasonic Velocity (U), Density ( $\boldsymbol{\rho})$, Adiabatic Compressibility ( $\boldsymbol{\beta}_{\text {ad }}$ ), Internal Molecular Free Length $\left(\mathbf{L}_{\mathbf{f}}\right)$, Acoustical Impedance $(\mathbf{Z})$, Molar Volume $\left(\mathbf{V}_{\mathbf{m}}\right)$, Rao's Constant $(\mathbf{R})$, Wada's constant $(\mathbf{W})$, Viscosity $(\boldsymbol{\eta})$, Internal Pressure $(\boldsymbol{\pi})$ and Free Volume $\left(\mathbf{V}_{\mathbf{f}}\right)$ for Molefraction of p-chlorotoluene with benzene at different temperatures $303.15 \mathrm{~K}, 308.15 \mathrm{~K}, 313.15 \mathrm{~K}$ and $318.15 \mathrm{~K}$.

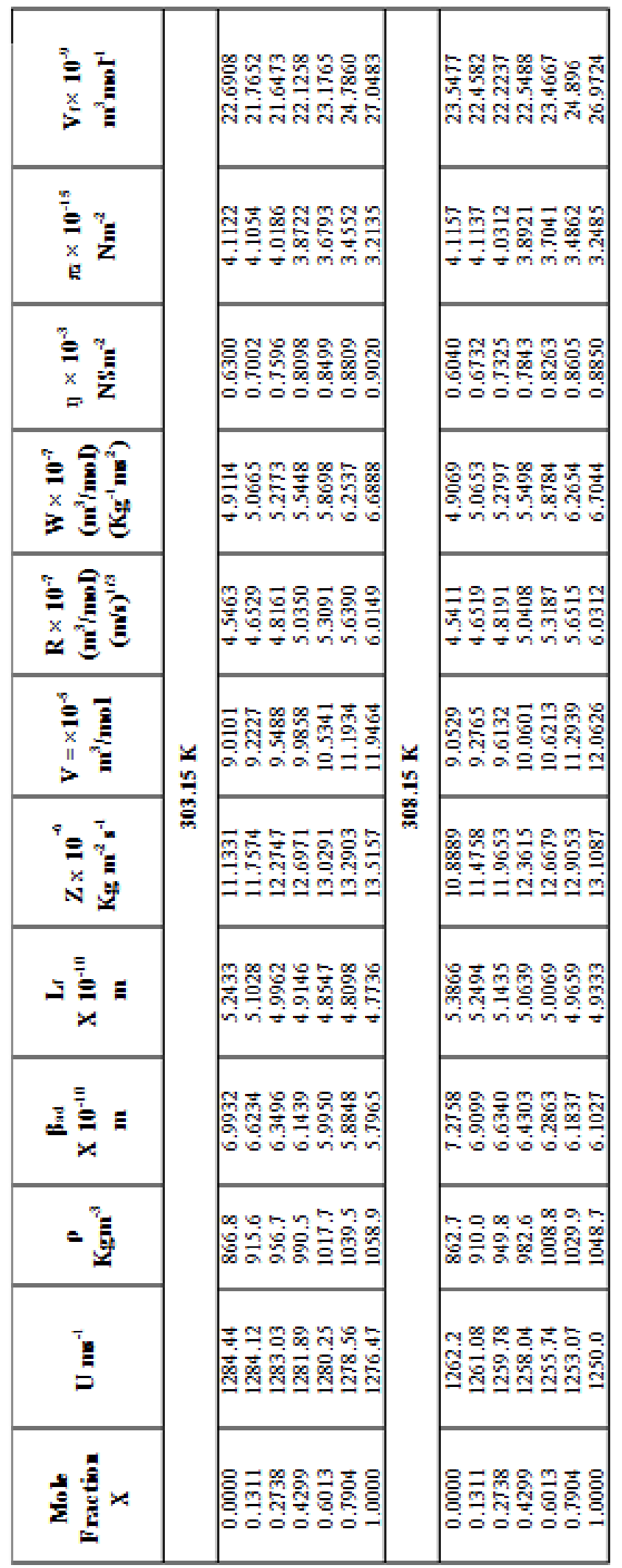


Table 1(continue). Ultrasonic Velocity (U), Density ( $\boldsymbol{\rho})$, Adiabatic Compressibility $\left(\boldsymbol{\beta}_{\text {ad }}\right)$, Internal Molecular Free Length $\left(\mathbf{L}_{\mathbf{f}}\right)$, Acoustical Impedance $(\mathbf{Z})$, Molar Volume $\left(\mathbf{V}_{\mathbf{m}}\right)$, Rao's Constant $(\mathbf{R})$, Wada's constant $(\mathbf{W})$, Viscosity $(\boldsymbol{\eta})$, Internal Pressure $(\boldsymbol{\pi})$ and Free Volume $\left(\mathbf{V}_{\mathbf{f}}\right)$ for Molefraction of p-chlorotoluene with benzene at different temperatures $303.15 \mathrm{~K}, 308.15 \mathrm{~K}, 313.15 \mathrm{~K}$ and $318.15 \mathrm{~K}$.

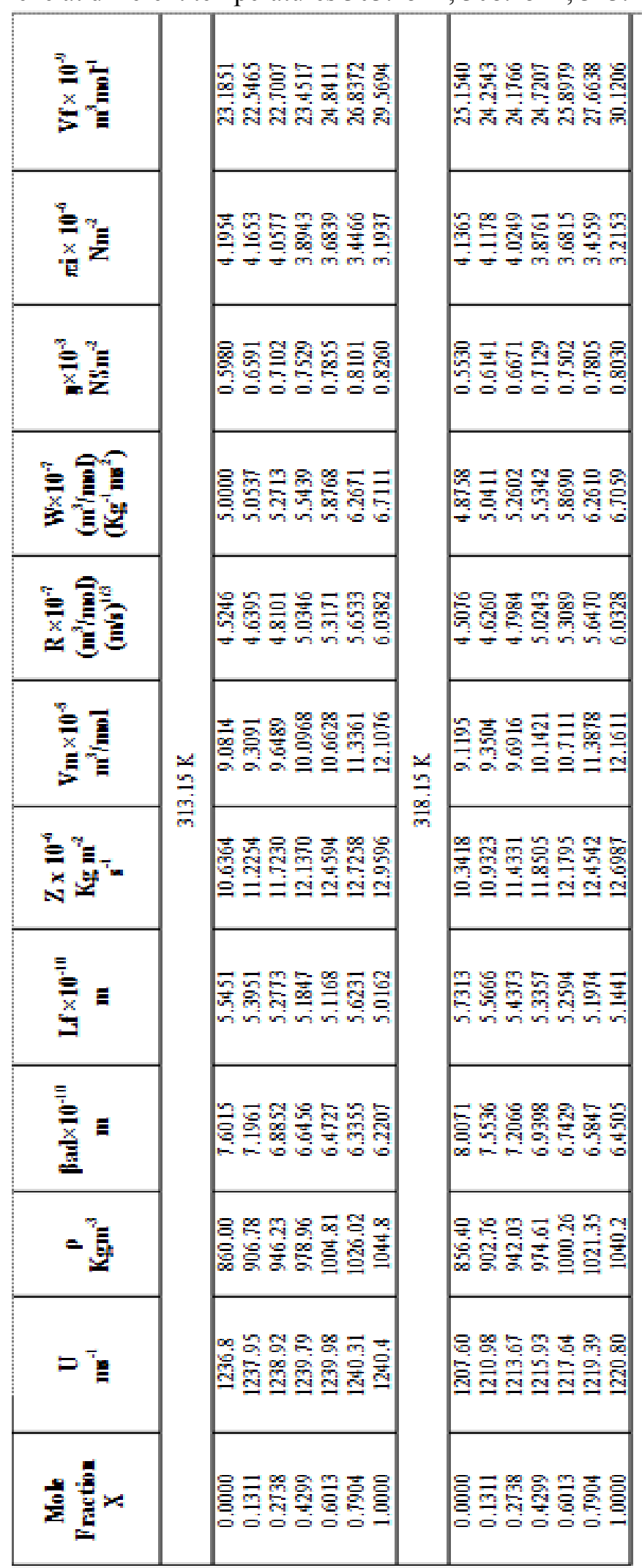




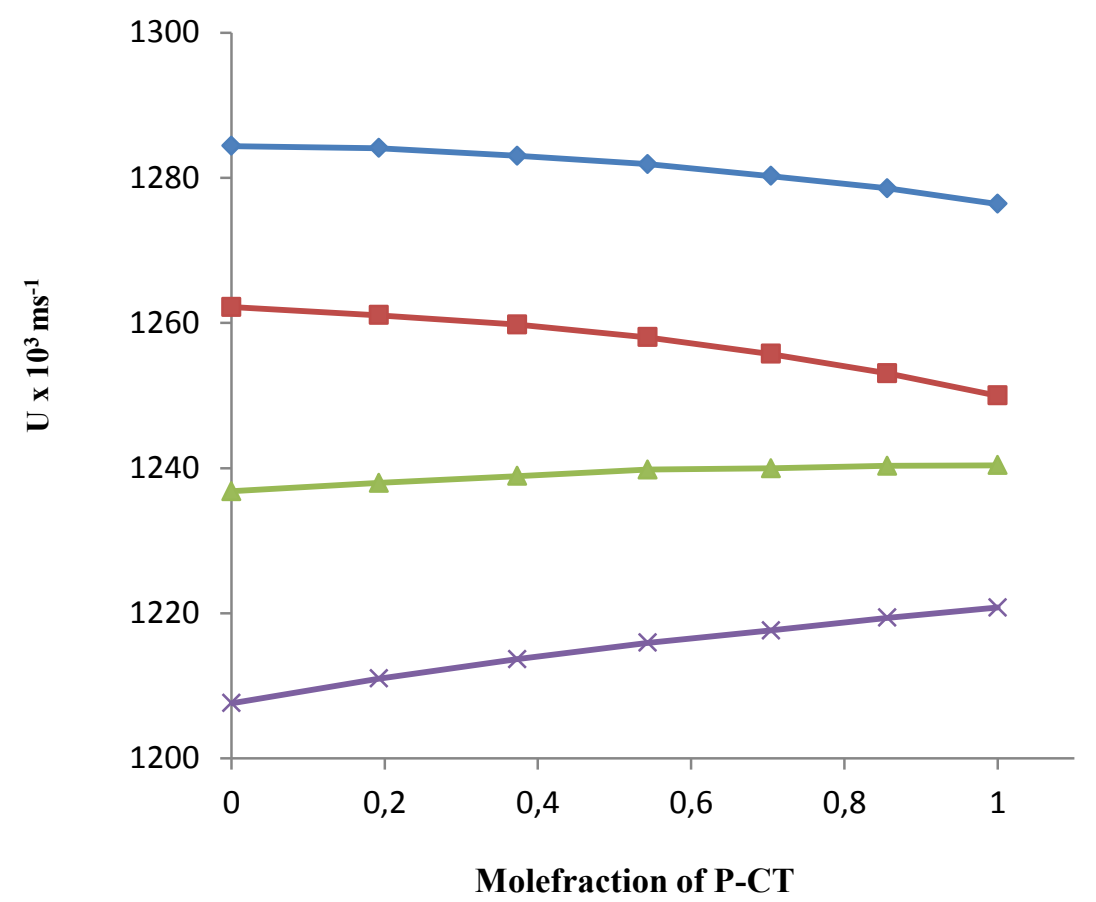

Fig. 1. Variation of Ultrasonic Velosity with Molefraction of p-chlorotoluene.

$\longrightarrow-303.15 \rightarrow-308.15 \rightarrow 313.15 \longrightarrow 318.15$

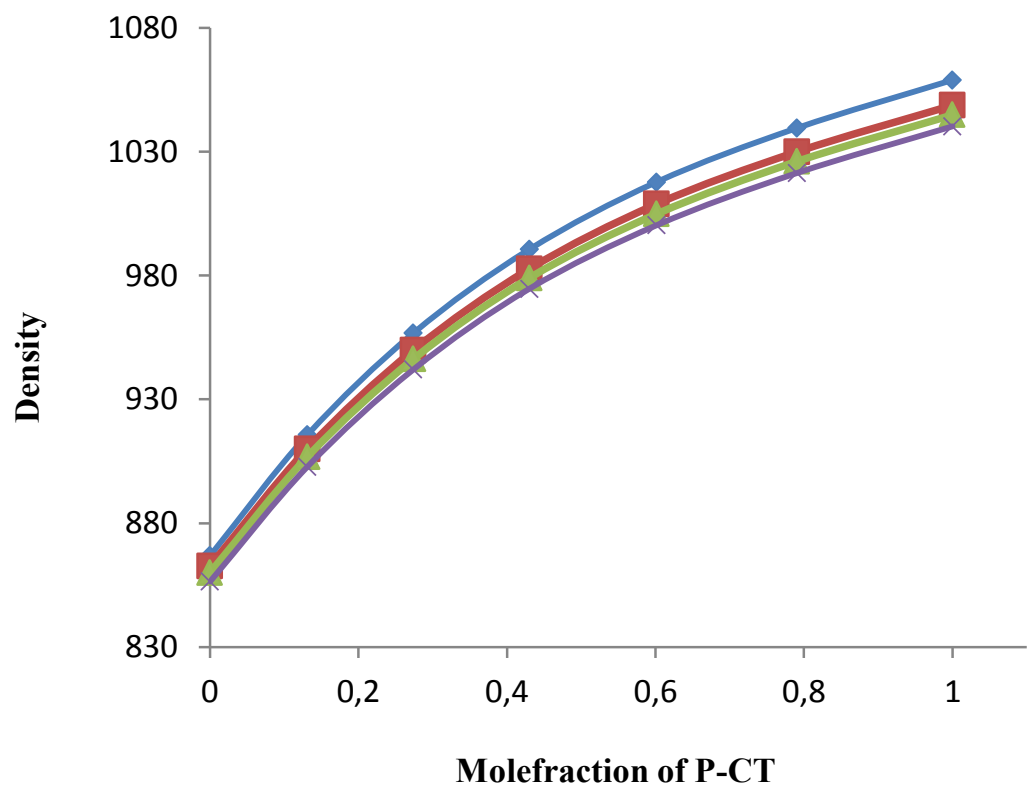

Fig. 2. Variation of Density with Molefraction of p-chlorotoluene.

$\longrightarrow-303.15 \rightarrow-308.15 \rightarrow-313.15 \rightarrow 318.15$ 


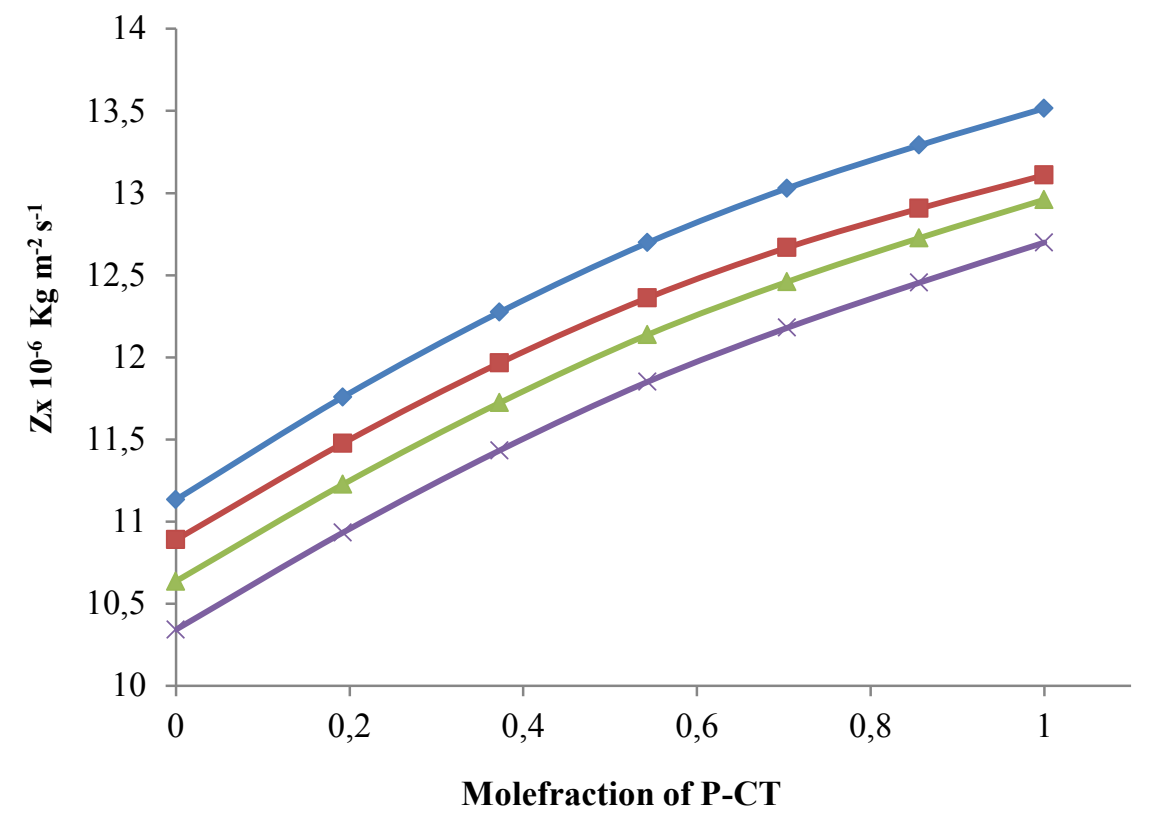

Fig. 3. Variation of Acoustical Impedance with Molefraction of p-chlorotoluene. $\rightarrow-303.15 \rightarrow-\square 08.15 \longrightarrow 313.15 \longrightarrow 318.15$

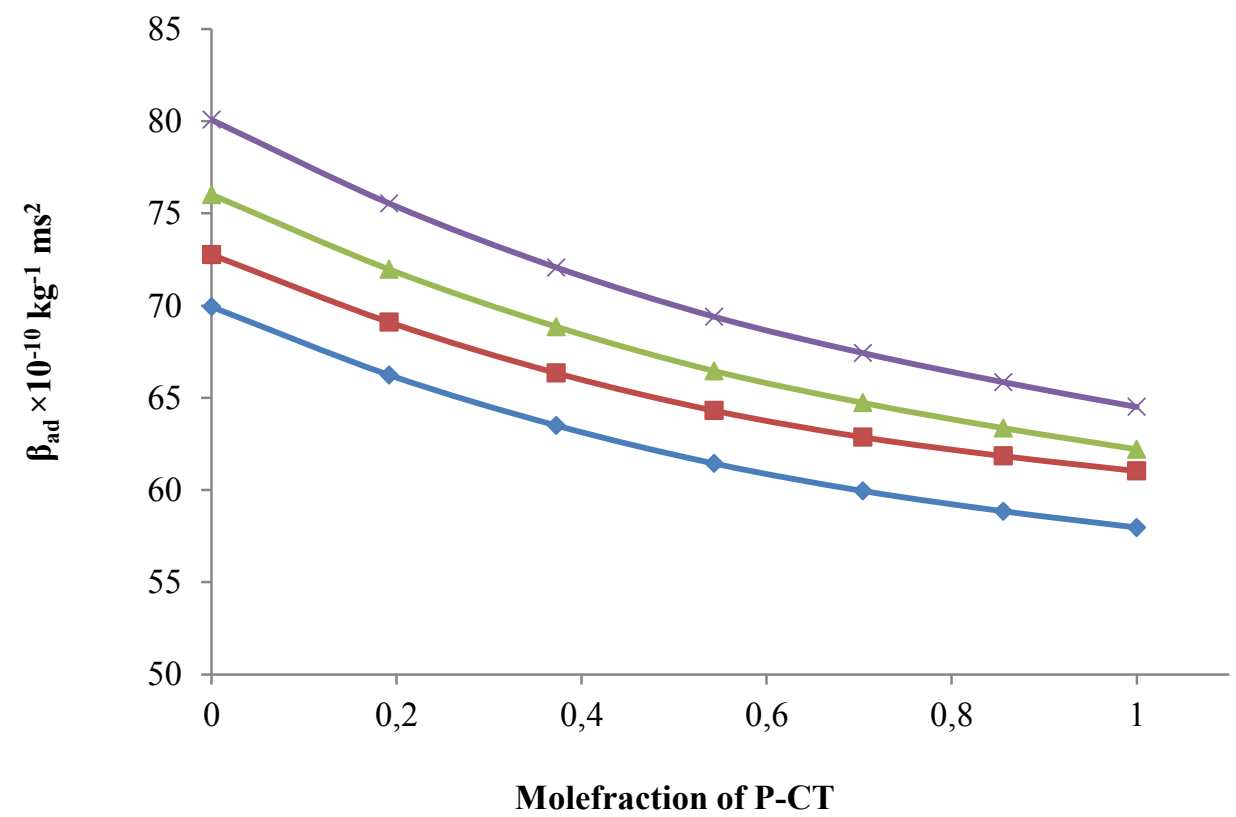

Fig. 4. Variation of Adiabatic Compressibility with Molefraction of p-chlorotoluene. $\multimap-303.15-208.15-313.15 \multimap 318.15$ 


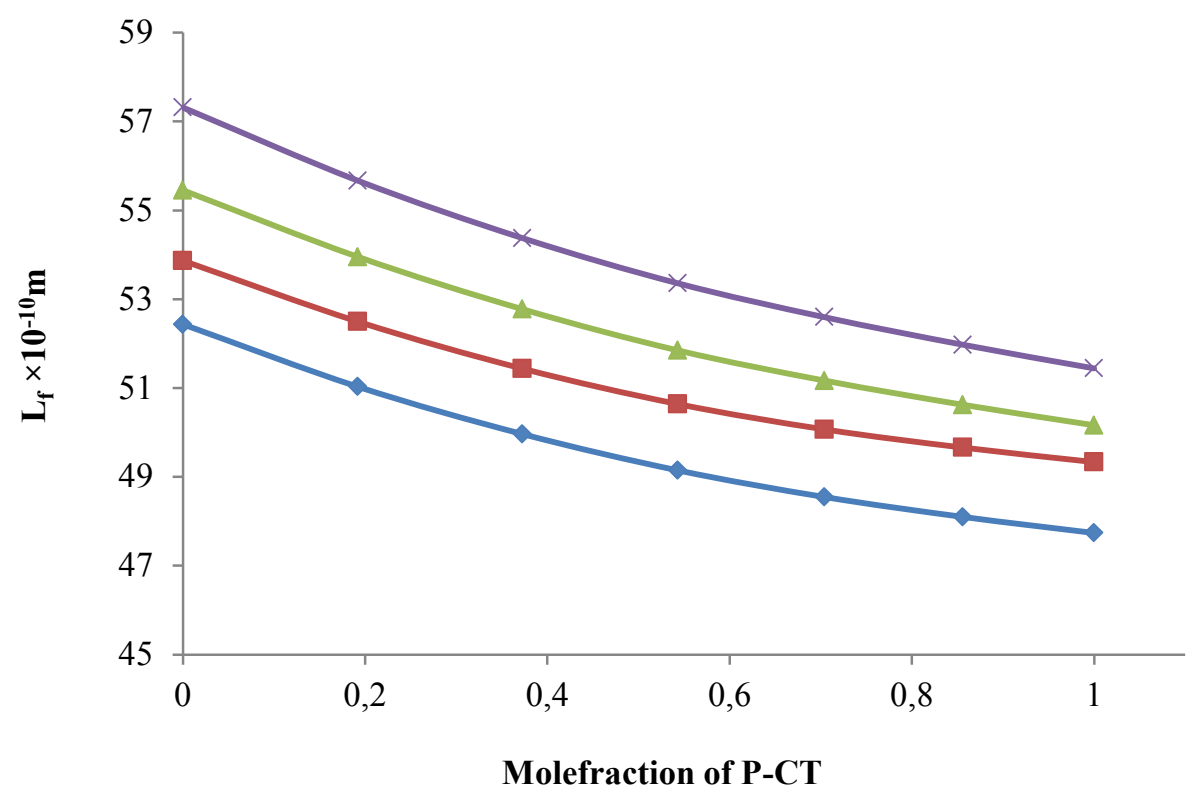

Fig. 5. Variation of Intermolecular freelength with Molefraction of p-chlorotoluene.

$\longrightarrow-303.15 \rightarrow-308.15 \rightarrow-313.15 \longrightarrow 318.15$

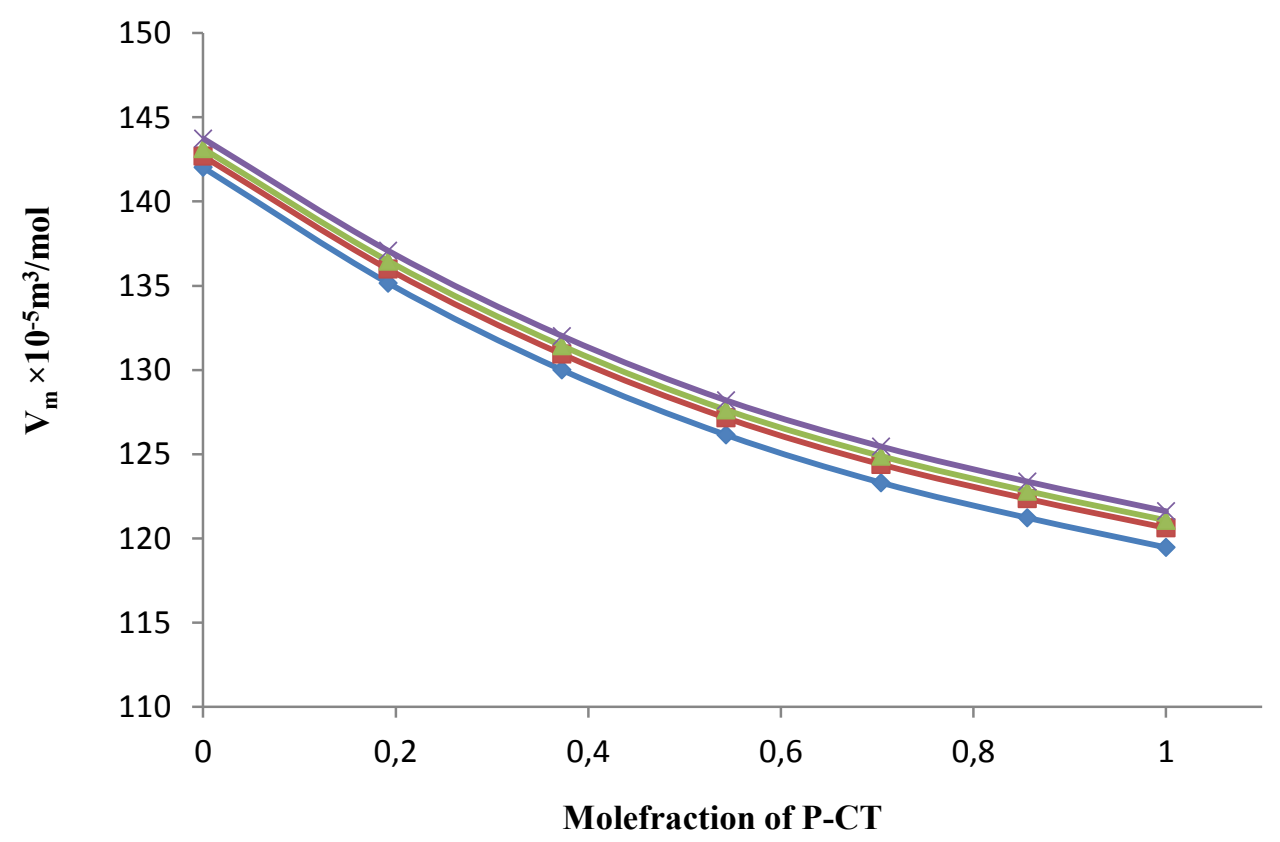

Fig. 6. Variation of Molar volume with Molefraction of p-chlorotoluene.

$\multimap-303.15-\square-308.15 \longrightarrow 313.15 \multimap 318.15$ 


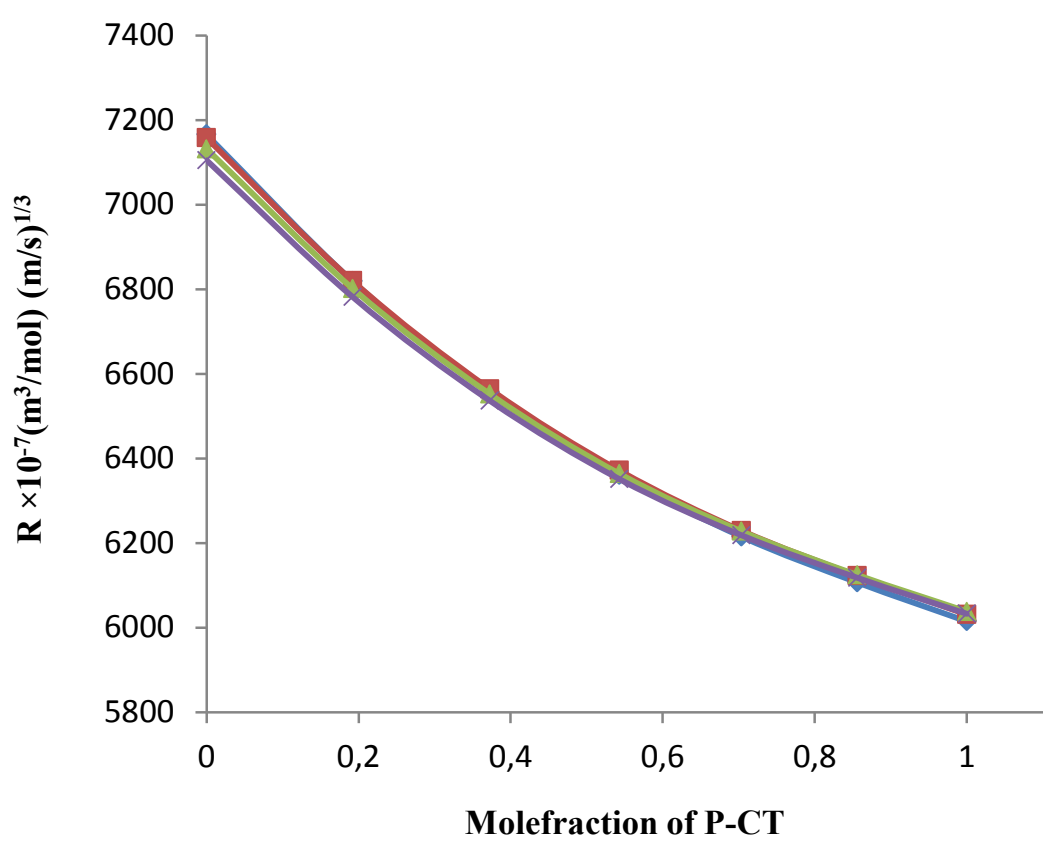

Fig. 7. Variation of Rao's Constant with Molefraction of p-chlorotoluene.

$\longrightarrow 303.15 \rightarrow-308.15 \longrightarrow 313.15 \rightarrow 318.15$

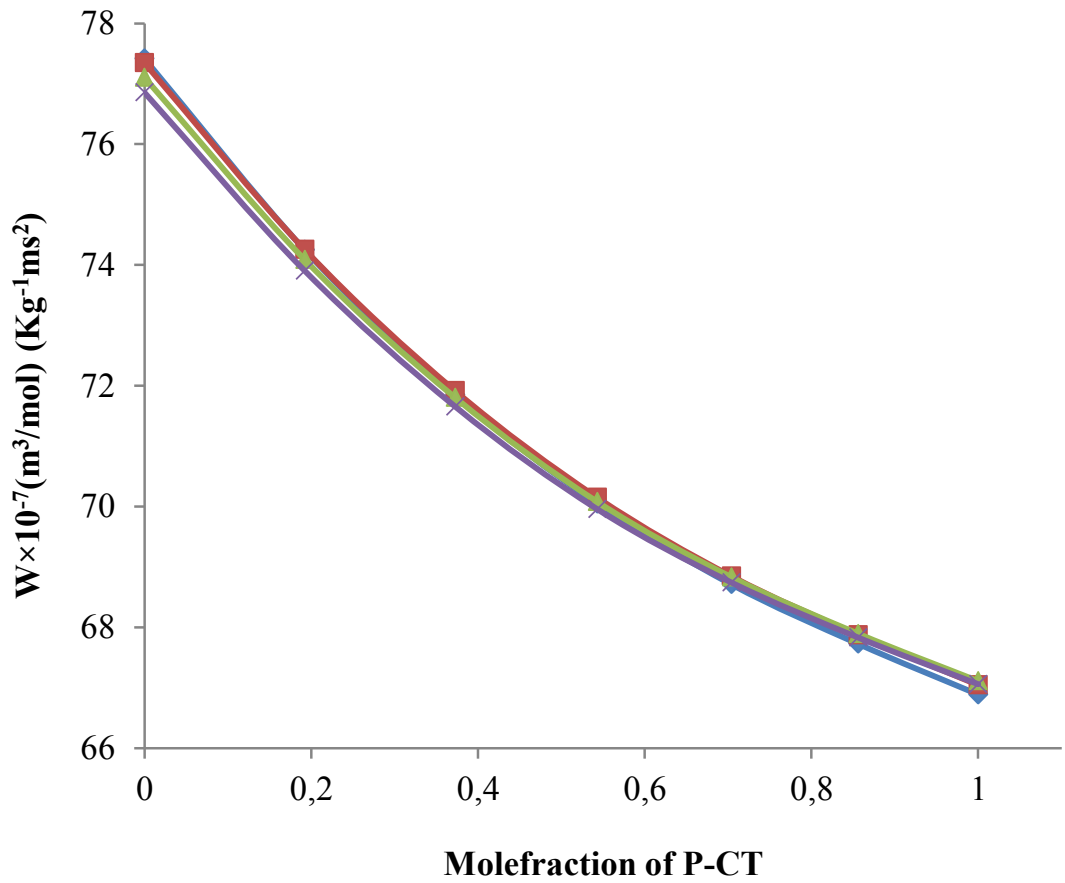

Fig. 8. Variation of Wada's Constant with Molefraction of p-chlorotoluene. $\longrightarrow-303.15-\square-308.15 \rightarrow 313.15 \rightarrow 318.15$ 


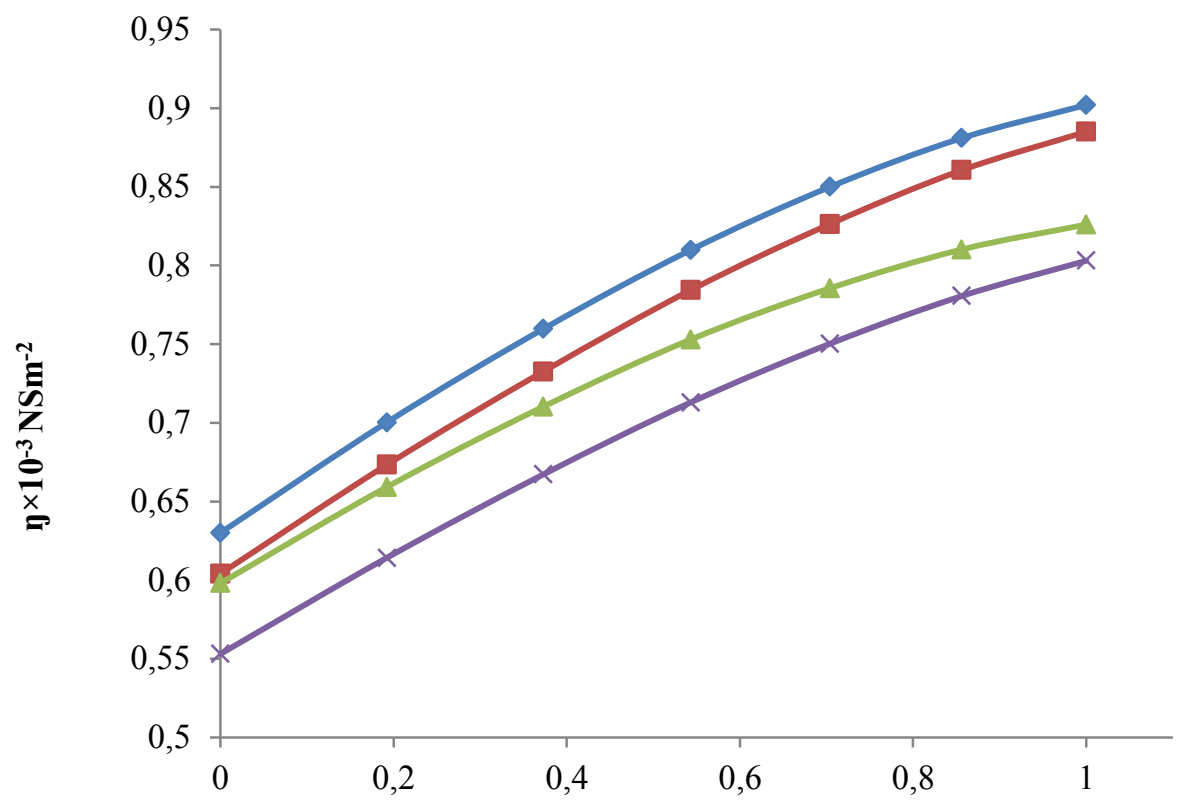

Molefraction of P-CT

Fig. 9. Variation of Viscosity with Molefraction of p-chlorotoluene. $\rightarrow-303.15 \rightarrow-308.15 \rightarrow 313.15 \rightarrow 318.15$

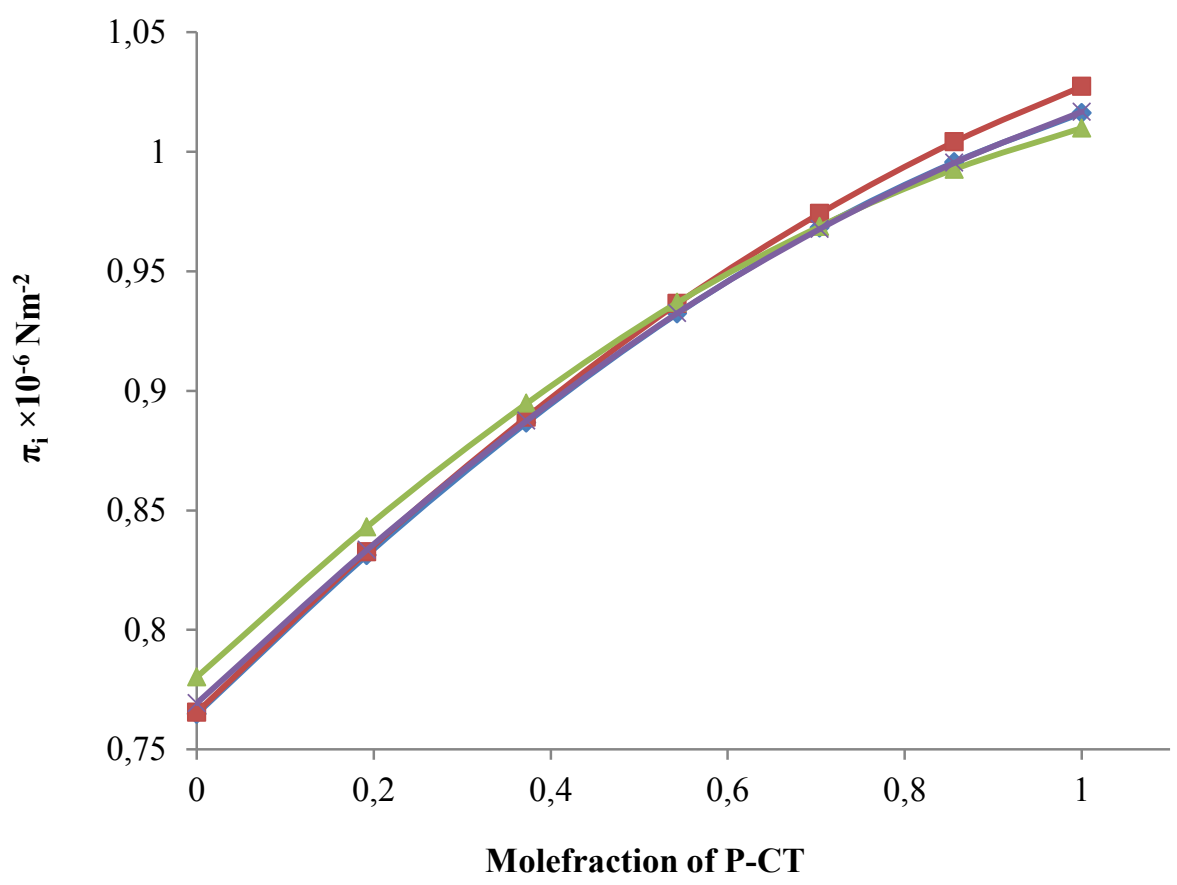

Fig. 10. Variation of Internal pressure with Molefraction of p-chlorotoluene. $\multimap-303.15 \rightarrow-308.15 \rightarrow 313.15 \multimap 318.15$ 


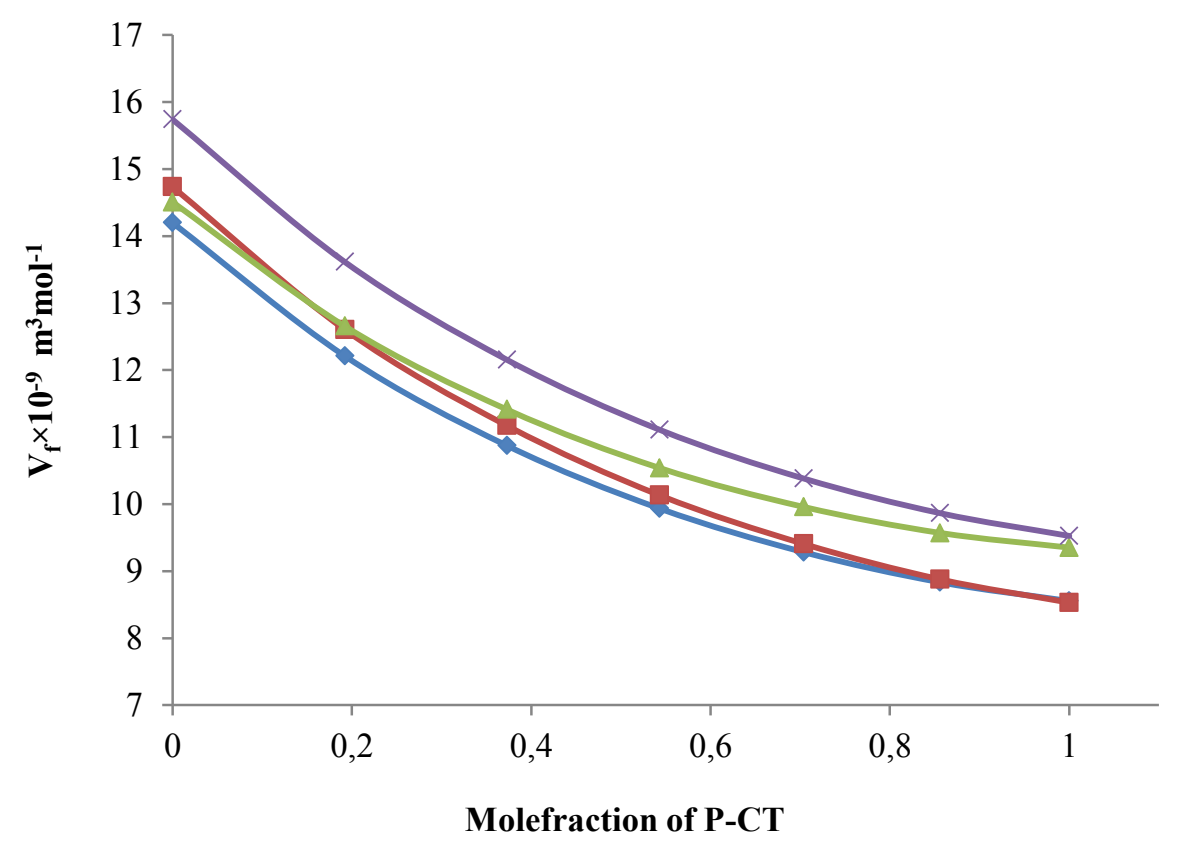

Fig. 11. Variation of Free volume with Molefraction of p-chlorotoluene.

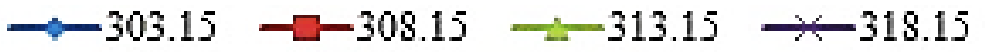

The free volume increases with increase molefraction of p-chlorotoluene [16]. The free volume is the space available for the molecules to move in an imaginary unit cell. It clearly indicates the existence of intermolecular interaction, due to which the structural arrangement is considerably affected. The Rao's constant and Wada's constant values are increases with increase concentration of p-chlorotoluene and decreases with the different temperatures and support the strong interactions.

\section{CONCLUSION}

The ultrasonic velocity, density, viscosity and other related parameters were calculated. The existence of type of molecular interactions in solute-solvent is confirmed from the $U, \rho$, $\beta_{\mathrm{ad}}, \mathrm{L}_{\mathrm{f}}, \mathrm{Z}, \mathrm{V}_{\mathrm{m}}, \mathrm{R}, \mathrm{W}, \eta, \pi$ and $\mathrm{V}_{\mathrm{f}}$ data. All the experimental determinations of acoustic parameters are strongly correlated between p-chlorotoluene with benzene.

\section{References}

[1] D. Vengatesulu, D. K. Prabhakara Rao, J. Acous. Soc. Ind. 1(4) (1999) 320.

[2] S. J. Askar Ali, K. Rajathi, A. Rajendran, J. Chem. Pharm. Res. 3(5) (2011) 348-358.

[3] V. D. Bhandarkkar, O. P. Chimankar, N. R. Pawar, J. Chem. Pharm. Res. 2(4) (2010) 873-877. 
[4] D. Bala Karuna Kumar, K. Rayapa Reddy, G. Srinivasa Rao, G. V. Rama Rao, C. Rambabu, J. Chem. Pharm. Res. 3(5) (2011) 274-280.

[5] G. V. Ramarao, A. V. Sarma, C. Rambabu, Ind. J. Pure Appl. Phys. 42 (2004) 820-826.

[6] G. V. Ramarao, A. V. Sarma, D. Ramachandran, C. Rambabu, Ind. J. Pure Appl. Phys. 43 (2005) 602-608.

[7] G. V. Ramarao, A. V. Sarma, P. B. Sandhyasri, C. Rambabu, Ind. J. Pure Appl. Phys. 45 (2007) 135-142.

[8] K. Sreekanth, D. S. Kumar, M. Kondaiah, D. Krishnarao, J. Chem. Pharm. Res. 3(4) (2011) 29-41.

[9] R. Venis, R. Rajkumar, J. Chem. Pharm. Res. 3(2) (2011) 878-885.

[10] Shilpa Mirikar, P. Pravina Pawar, K. Govind Bichile, J. Chem. Pharm. Res. 3(5) (2011) 306-310.

[11] A. K. Nain, J. Chem. Thermodynamics 59 (2013) 49-64.

[12] M. Aravinthraj, S. Venkatesan, D. Meera, J. Chem. Pharm. Res. 3(2) (2011) 623.

[13] P. S. Agrawal, M. S. Wagh, L. J. Paliwal, Archives of Applied Science Research 3(2) (2011) 29.

[14] R. J. Forte, W. R. Moore, Trans. Faraday Soc. 61 ( 1965) 2102.

[15] P. B. Agrawal, Mohd Indrees Mohd Siddique, M. L. Narwade, Ind. J. Chem. 42A(5) (2003) 1050.

[16] S. J. Askar Ali, J. Chem. Pharm. Res. 4(1) (2012) 617-632.

[17] N. Santhi, P. Sabarathinam, G. Alamelumangai, J. Madhumitha, M. Emayavaramban, International Letters of Chemistry, Physics and Astronomy 5 (2012) 1-7.

[18] N. Santhi, P. L. Sabarathinam, G. Alamelumangai, J. Madhumitha, M. Emayavaramban, International Letters of Chemistry, Physics and Astronomy 5 (2012) 59-71.

[19] N. Santhi, P. L. Sabarathinam, J. Madhumitha, G. Alamelumangai, M. Emayavaramban, International Letters of Chemistry, Physics and Astronomy 2 (2013) 18-35.

[20] M. Durga Bhavani, A. Ratnakar, Ch. Kavith, International Letters of Chemistry, Physics and Astronomy 5 (2013) 1-6.

[21] S. S. J. Srinivas, B. Tulasi Koteswari Bai, K. Babu Rao, K. Narendra, M. Sarath Babu, International Letters of Chemistry, Physics and Astronomy 10(2) (2013) 151-158.

[22] C. H. Srinivasu, K. Anil Kumar, S. K. Fakruddin, K. Narendra, T. Anjaneyulu, International Letters of Chemistry, Physics and Astronomy 13 (2013) 1-7.

[23] G. Alamelumangai, N. Santhi, International Letters of Chemistry, Physics and Astronomy 5 (2014) 124-133. 